\title{
Impact of temporomandibular disorders on oral health-related quality of life of institutionalized elderly people
}

\author{
Impacto da disfunção temporomandibular na qualidade de vida \\ relacionada à saúde bucal em idosos institucionalizados
}

\author{
Victório Poletto Neto* \\ Gabriela Lamas Lamas** \\ Mauro Elias Mesko ${ }^{* * *}$ \\ Fernanda Valentini Mioso ${ }^{* * *}$ \\ Marcos Britto Corrêa ${ }^{* * * * *}$ \\ Tatiana Pereira-Cenci*
}

\section{Abstract}

Objective: to assess the characteristics associated with temporomandibular disorders (TMD) and their impact on oral health-related quality of life (OHRQoL) of institutionalized elderly people. Subjects and method: it was a cross-sectional study performed in 30 private institutions for the elderly. The data collected included the TMD questionnaire and clinical evaluation assessed by the Research Diagnostic Criteria/Temporomandibular Disorders (RDC/TMD), as well as the OHIP-49 questionnaire for OHRQoL. Results: twenty-four institutions accepted to participate in the study $(\mathrm{n}=375$ with 133 fit for answering both questionnaires). Considering the characteristics, tinnitus was the most frequent symptom reported, while $98.5 \%$ of the research participants did not present myofascial pain. Disc displacement was observed in $26.3 \%$, while $93 \%$ of individuals did not present chronic pain. Severe depression was found in $23.3 \%$ of the elderly with $24.1 \%$ presenting moderate levels of non-specific physical symptoms, including pain. Poisson regression analysis showed that the characteristics reported were associated with a negative impact on OHRQoL. Conclusion: the domain-specific analysis showed that all domains were affected negatively by TMD characteristics and higher levels of depression are associated with a negative impact on OHRQoL.

Keywords: Elderly people. Oral health-related quality of life. Temporomandibular disorders. Facial pain. Depression.

\section{Introduction}

Temporomandibular disorder (TMD) consists of a series of conditions that affect the orofacial joint and muscles, leading to mandibular movement restriction, loss of masticatory efficiency, pain or tenderness, pain during mandibular movement, facial pain, headache, and joint sounds, the latter being the most frequent ${ }^{1}$. Associated with malocclusion and parafunctions, these symptoms may lead to microtraumas in the temporomandibular joint and further deterioration of condyle and articular disc.

Studies on the risk factors for the development of TMD indicate biopsychological aspects as the key to TMD and highlight some factors as sleep disturbances, poor oral hygiene, accumulation of comorbidities, oral parafunction, and even genetic markers for the development of clinical TMD ${ }^{2}$. The TMD affects psychological conditions and masticatory ability, influencing the oral health-related quality of life (OHRQoL) of individuals ${ }^{3}$. Subjective indicators used for general and oral health showed that TMD plays an important role on the quality of life and, despite the numerous methods used to assess OHRQoL and $\mathrm{TMD}^{4-6}$, the assessment of elderly subjects is rare. 
Physiological changes in the tone of facial and masticatory muscles, oral manifestations of systemic diseases, and decreased sensory perception and motor skills of the remaining structures of the oral cavity resulting from aging only contribute for TMD and the development of chronic orofacial pain in elderly people ${ }^{7}$. Furthermore, the higher severity of TMD signs and symptoms in edentulous subjects ${ }^{8,9}$ has already been proven and it is important to be considered, whereas the most prevalent edentulous population is aged 6574 years ${ }^{10}$. Thus, this study aimed to evaluate patient characteristics and the diagnosis of orofacial pain through the Research Diagnostic Criteria/ Temporomandibular Disorders (RDC/TMD) and their association with the impact on OHRQoL in a private elderly community dwelling.

\section{Subjects and method}

This cross sectional study was approved by the local Research Ethics Committee (217/2011) and it was performed between August 2013 and October 2014, in Pelotas, which is a city located in the southern region of Brazil with an elderly population of about 50,000 inhabitants in 2010. Thirty private elderly homes were found in the city. All homes were contacted and invited to participate, and six of them refused. All elderly residents were informed about the objective of the investigation and invited to participate $(\mathrm{n}=375)$. Written and informed consent from the home and the individuals were signed $(\mathrm{n}=133)$ as they met the following inclusion criteria: agree to participate, being able to answer the questions, and having teeth in both upper and lower arches with or without the use of prosthesis (removable or complete denture). The main reasons for exclusion were related to the inability of answering the questions. This included patients with stroke, diagnosis of advanced Alzheimer, senile dementia, moderate-severe schizophrenia, bedridden patients unable to answer, individuals with infantile paralysis, visual and hearing impairments, individuals who initiated the research and quit mid-interview as they found it too tiring, individuals with bipolar disorder and mental disability, and patients who left the house or died during the research.

The Research Diagnostic Criteria/Temporomandibular Disorders (RDC/TMD) were used for temporomandibular disorder (TMD) diagnosis. Two previously trained and calibrated dentists were selected for clinical assessment of signs of TMD according to the diagnostic criteria used. Participants' age, gender, and educational level were collected. A validated axis II instrument was used $^{11}$. Following the protocol for axis II score, the graded chronic pain was assessed as low disability - low intensity (Grade I) and high intensity (Gra- de II); and as high disability - moderately limiting (Grade III) and severely limiting (Grade IV). Levels of depression were also assessed and later categorized as normal $<0.535$, moderate $>0.536$ up to 1.104 , and severe $\geq 1.105$. The levels of non-specific physical symptoms, including pain-related issues or not, were assessed and categorized as normal $\leq 0.5$, moderate 0.6 to 1 , and severe $\geq 1^{12}$.

The Portuguese version of the OHIP-49 questionnaire $^{13}$ was used to assess the participants' oral health-related quality of life (OHRQoL). The subjects were asked to rate the frequency in which they had experienced the impact of each oral health impact profile (OHIP) domain on a five-point Likert scale ( $4=$ very often, $3=$ fairly often, $2=$ occasionally, $1=$ hardly ever, $0=$ never $)$. The OHIP scores ranging from 0 (very good QoL) to 196 (very poor QoL) were calculated.

The variables related to RDC/TMD and OHIP49 were submitted to descriptive analysis, resulting in absolute and relative frequencies of categorical variables and means and standard deviations of numerical variables through the Stata 11.0 software (Statacorp, Texas, USA). Associations between RDC/TMD and OHRQoL were explored using bivariate Poisson regression analysis to yield the average ratios and their $95 \%$ confidence intervals. The average ratio is the arithmetic average ratio of the scores obtained by the OHIP49 between exposed and non-exposed groups.

\section{Results}

Two hundred and twenty-three subjects did not participate in the study, whereas 184 subjects had a disease that impaired their inclusion and 36 subjects had no teeth/prosthesis, as stated in the exclusion criteria. One hundred and fifty-two individuals were included in the research and 19 refused to participate, representing a response rate of $87.5 \%$. Regarding the subjects included, 102 were women $(76.7 \%)$, with mean age of $76( \pm 12.4)$ years. As for education, 115 individuals reported having some level of education, considering that $49.6 \%$ reported attending elementary school, $32.2 \%$ high school, and $18.3 \%$ higher education.

Table 1 shows participant distribution according to axis I of the Research Diagnostic Criteria (RDC). Among these characteristics, the most frequent injury related was tinnitus followed by click and uncomfortable bite. Clenching at both night and day times were less reported by subjects of this sample. Table 2 shows the distribution profile of the diagnosis and the elderly evaluated through axes I and II. In axis I, almost no participant presented myofascial pain and $26.3 \%$ of subjects had disc displacement with reduction - typical signs of temporomandibular disorder (TMD). In axis II, $93 \%$ of subjects did not present chronic pain. As 
for depression, $22.6 \%$ of patients included had moderate depression, while $23.3 \%$ presented severe levels. Regarding non-specific physical symptoms, the individuals presented $24.1 \%$ of moderate and $15.0 \%$ of severe symptoms, including pain.

The impact on oral health-related quality of life (OHRQoL) showed a total mean OHIP-49 in the sample score of $16.0( \pm 19.4)$. Considering the different domains of the quality of life questionnaire, mean and standard deviations are presented as follows: functional limitation (3.3 \pm 4.2$)$, physical pain $(4.2 \pm 5.2)$, psychological discomfort $(2.7 \pm 4.5)$, physical disability $(2.6 \pm 4)$, psychological disability $(1.6 \pm 3.6)$, social disability $(1.0 \pm 2.9)$, and disability index $(5.5 \pm 1.8)$.

Table 1 - Research diagnostic criteria characteristics/axis I in the institutionalized elderly $(n=133)$

\begin{tabular}{|c|c|c|}
\hline Variables & $\begin{array}{l}\text { Absolute Freq. } \\
\qquad(\mathrm{N})\end{array}$ & $\begin{array}{c}\text { Relative Freq. } \\
(\%)\end{array}$ \\
\hline \multicolumn{3}{|l|}{ Click } \\
\hline No & 107 & 80.5 \\
\hline Yes & 26 & 19.6 \\
\hline \multicolumn{3}{|l|}{ Crackle } \\
\hline No & 121 & 91.0 \\
\hline Yes & 12 & 9.0 \\
\hline \multicolumn{3}{|l|}{ Nighttime Clenching } \\
\hline No & 118 & 88.8 \\
\hline Yes & 15 & 11.3 \\
\hline \multicolumn{3}{|l|}{ Daytime Clenching } \\
\hline No & 124 & 93.2 \\
\hline Yes & 9 & 6.8 \\
\hline \multicolumn{3}{|c|}{ Fatigue/Jaw pain upon waking up } \\
\hline No & 122 & 91.8 \\
\hline Yes & 11 & 8.3 \\
\hline \multicolumn{3}{|l|}{ Tinnitus } \\
\hline No & 90 & 67.7 \\
\hline Yes & 43 & 32.3 \\
\hline \multicolumn{3}{|l|}{ Uncomfortable Bite } \\
\hline No & 109 & 82.0 \\
\hline Yes & 24 & 18.1 \\
\hline
\end{tabular}

Source: authors.
Table 2 - Patient distribution according to profile and diagnosis (Research Diagnostic Criteria/axis I and II; $n=133$ )

\begin{tabular}{|c|c|c|}
\hline Variables & $\begin{array}{l}\text { Absolute Freq. } \\
(\mathrm{N})\end{array}$ & $\begin{array}{l}\text { Relative Freq. } \\
(\%)\end{array}$ \\
\hline \multicolumn{3}{|l|}{ Axis I } \\
\hline \multicolumn{3}{|l|}{ Muscle disorder } \\
\hline No diagnosis & 131 & 98.5 \\
\hline Myofascial pain & 2 & 1.50 \\
\hline \multicolumn{3}{|l|}{ Disc displacement } \\
\hline No diagnosis & 98 & 73.7 \\
\hline $\begin{array}{l}\text { Disc displacement with } \\
\text { reduction }\end{array}$ & 35 & 26.3 \\
\hline \multicolumn{3}{|l|}{ Axis II } \\
\hline \multicolumn{3}{|l|}{ Graded chronic pain } \\
\hline No pain & 124 & 93.2 \\
\hline Low disability & 1 & 0.8 \\
\hline Low intensity & 5 & 3.8 \\
\hline High intensity & 3 & 2.3 \\
\hline \multicolumn{3}{|l|}{ Depression } \\
\hline Normal & 72 & 54.1 \\
\hline Moderated & 30 & 22.6 \\
\hline Severe & 31 & 23.3 \\
\hline \multicolumn{3}{|c|}{$\begin{array}{l}\text { Non-specific physical symptoms } \\
\text { including pain }\end{array}$} \\
\hline Normal & 81 & 60.1 \\
\hline Moderated & 32 & 24.1 \\
\hline Severe & 20 & 15.0 \\
\hline
\end{tabular}

Table 3 shows the association between patient characteristics (RDC/TMD) and OHRQoL. The presence of click, crackle, nighttime clenching, daytime clenching, fatigue/jaw pain upon waking up, and tinnitus were associated with higher impact on OHRQoL. It could be observed that all domains were affected by the characteristics reported by the patients, with the presence of these symptoms associated with the highest impact on OHRQoL. Among the most affected domains are functional limitations, physical pain, psychological discomfort, and psychological disability. A higher magnitude of impact was observed in general for the presence of fatigue/jaw pain upon waking up and crackle, affecting many domains of the OHIP-49.

Table 4 shows the association between variables of axes I and II (RDC / TMD) and the impact on OHRQoL in the institutionalized elderly. Regarding axis I, subjects with disc displacement had no impact in relation to the domains. When analyzing axis II, all domains were affected by the level of depression, increasing the impact with increased level of depression. In relation to non-specific physical symptoms related to pain, all domains were affected by increasing the impact with increased severity of symptoms. 


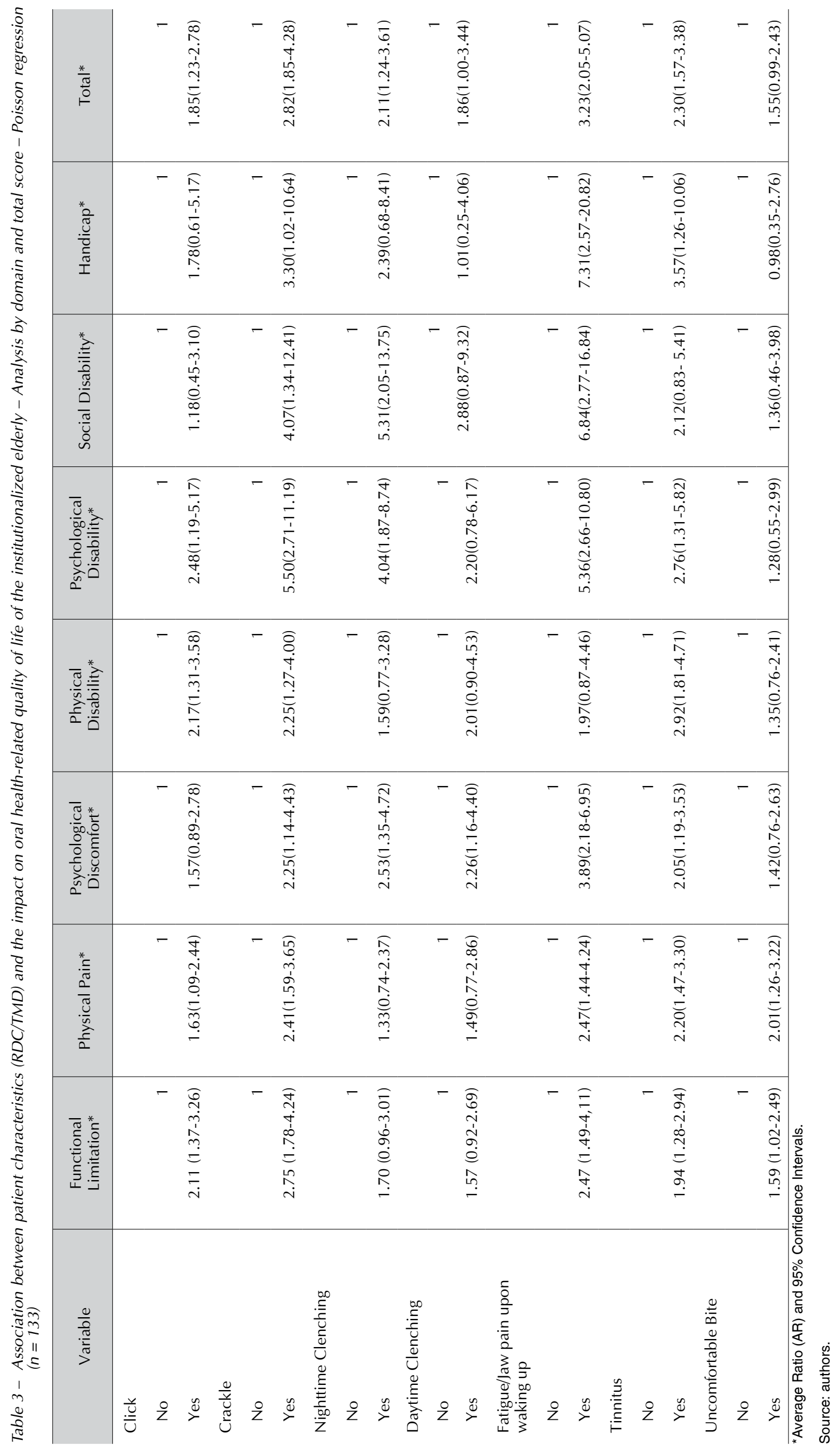




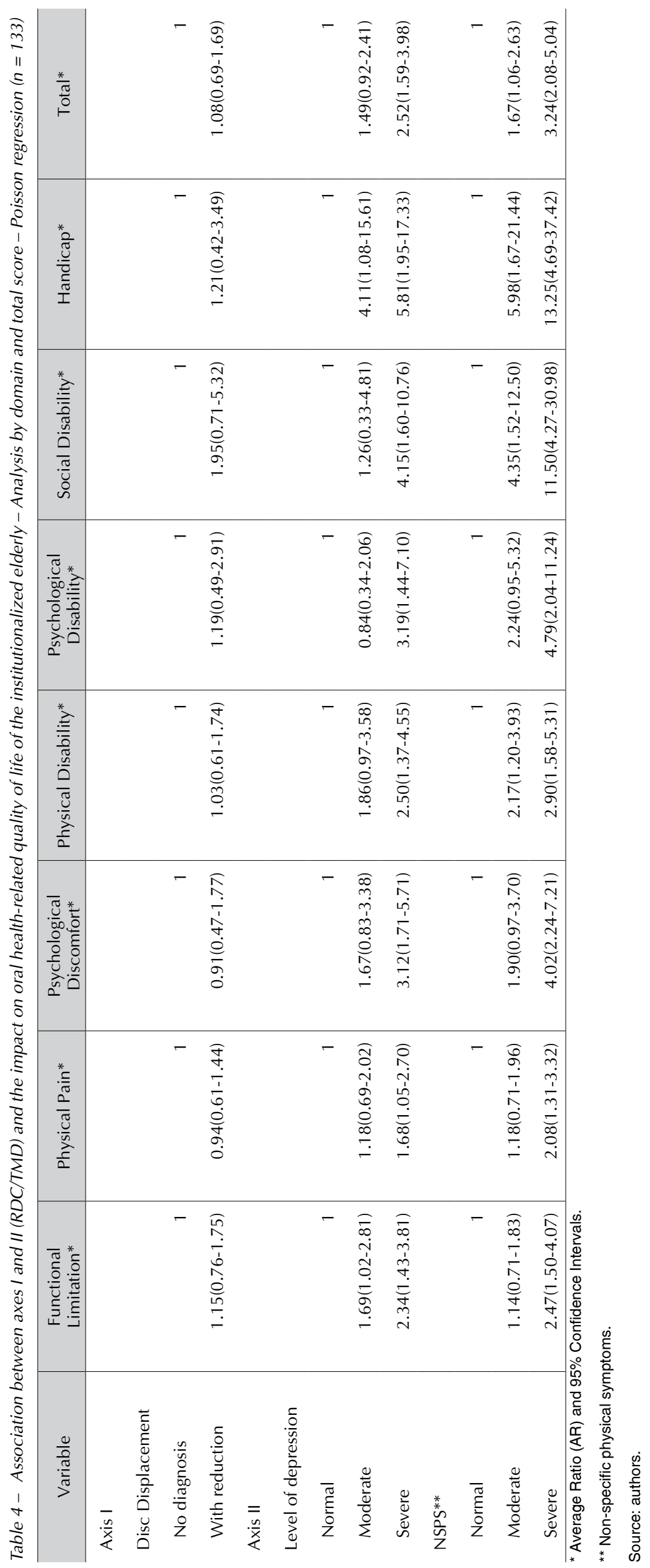




\section{Discussion}

The results of this study showed that patient characteristics evaluated for temporomandibular disorder (TMD) through the Research Diagnostic Criteria/Temporomandibular Disorder (RDC/TMD) were associated with the oral health-related quality of life (OHRQoL) of the elderly, which corroborates several previous studies ${ }^{14-17}$. However, clinical features assessed in axis I of the RDC/TMD did not show association with OHRQoL. Subjective symptoms reported by patients have been more closely associated with the impact on the clinical symptoms of OHRQoL. Thus, the variables related to axis II of the RDC/TMD seems to be more important than those of axis I (clinical diagnosis) for assessing quality of life. Probably, the subjective nature of both characteristics and symptoms reported by patients, as the assessment of $\mathrm{OHRQoL}$, is the main reason for that.

Quality of life has been affected by changes related to TMD in the elderly assessed. Results from the self-reported results also showed that oral aggravations affect the quality of life, with fatigue/jaw pain upon waking up and crackle as the most important symptoms in all domains of the oral health impact profile (OHIP). These data corroborate a previous study in which the injury most frequently reported was tinnitus, which is associated with $\mathrm{TMD}^{18}$. However, the specific cause of this condition is yet unknown.

Overall, the OHIP domains related to psychological aspects were most heavily impacted ${ }^{7}$. A possible explanation for these findings may refer to characteristics associated with aging, considering the amount of determinants that trigger psychosocial problems grow with increasing age ${ }^{3}$. In addition, the continued therapeutic assistance community requirement, abandonment, and loss of contact with family members and friends may also contribute to the psychological impairment of the individual.

Axis II of the RDC/TMD shows that depression and non-specific physical symptoms related to pain were affected proportionally when the severity of these symptoms was higher. Depression and anxiety in these patients may change tolerance and perception regarding symptoms ${ }^{19}$ and therefore require special attention ${ }^{20}$.

The presence of disc displacement with reduction is a characteristic sign of TMD ${ }^{1}$. Patients with TMD presenting arthralgia or disc displacement without reduction present worse conditions of OHRQoL than patients diagnosed with disc displacement with reduction ${ }^{14-17}$. These results were not found in our study. Only two subjects were diagnosed with myofascial pain, while about $7 \%$ had some degree of chronic pain assessed, preventing the association analysis of these factors with OHRQoL. If patients with disc displacement may be diagnosed as asymptomatic, except for joint sounds, there is reason to believe that non-painful conditions have less impact on the quality of life, considering that pain is one of the important aspects to be measured in cases of TMD ${ }^{19}$.

The distribution of characteristics reported in the subjects assessed by the RDC showed higher presence of click than crackles, which may be considered positive. This is because even in cases in which crackles are not associated with mouth opening limitations, it also somewhat limits function and potentially causes lockjaw and pain, unlike click, which is less associated with these symptoms.

Some studies suggest that TMD has a higher impact on OHRQoL than other orofacial conditions ${ }^{21,22}$, such as caries and periodontal disease, which were evaluated in our work. In this regard, more research is needed to confirm our findings. The cross-sectional design prevents relations of cause and effect by limiting the interpretation of results. The fact that this research has only been conducted in private institutions may affect the extrapolation of results. However, over $90 \%$ of the institutionalized elderly were using the private network in the sample assessed.

Another important issue concerns the response rate. A study assessing the prevalence of TMD symptoms in elderly people aged 65 and 75 years presented response rates around $72 \%$ for both ages ${ }^{23}$. Despite the difference between RDC/ TMD and the methodology used in that study, both questionnaires could be considered lengthy and time-consuming for patients. Indeed, the exclusion criteria limits higher sample sizes in institutionalized patients. Nevertheless, our response rate was similar as reported elsewhere ${ }^{23}$. It is worth mentioning that patients with other severe morbidities will live with TMD without even reporting many of its pain characteristics, which could lead to biased results ${ }^{24}$.

\section{Conclusion}

Functional limitation, physical pain, psychological discomfort, and psychological disability are associated with negative impact on the oral health-related quality of life of the institutionalized elderly and should be considered in temporomandibular disorder diagnosis and treatment.

\section{Acknowledgments}

The authors would like to thank Fapergs for the financial support and Aline de Oliveira Gomes, Caroline Scheneider de Oliveira, Karen Bichet Calcagno, and Matheus Völz Cardoso for their assistance. 


\section{Resumo}

Objetivo: avaliar as características associadas às disfunções temporomandibulares (DTM) e seu impacto na qualidade de vida relacionada a saúde bucal (OHRQoL) em idosos institucionalizados. Sujeitos e método: este foi um estudo transversal, realizado em trinta instituições privadas de idosos. Os dados coletados incluíram um questionário e uma avaliação clínica de DTM por meio do instrumento Research Diagnostic Criteria/ Temporomandibular Disorders (RDC/TMD) e do questionário OHIP 49 para OHRQoL. Resultados: vinte e quatro instituições autorizaram a realização do estudo, ( $\mathrm{n}=375$ com 133 idosos aptos a responder ambos os questionários). Dentre as características, o agravo mais frequentemente relatado foi a ocorrência de zumbido no ouvido, enquanto $98,5 \%$ dos participantes da pesquisa não apresentaram dor miofascial. Deslocamento de disco foi observado em $26,3 \%$, enquanto $93 \%$ dos indivíduos não apresentaram dor crônica. Depressão severa foi encontrada em $23,3 \%$ dos idosos avaliados, com $24,1 \%$ apresentando grau moderado de sintomas físicos não específicos, incluindo dor. Análise da regressão de Poisson apresentou que as características relatadas estiveram associadas a impacto negativo na qualidade de vida relacionada à saúde bucal. Conclusão: realizando a análise por domínios, todos os domínios foram negativamente afetados pelas características da DTM, e os níveis maiores de depressão estão associados a um impacto negativo na OHRQoL.

Palavras-chave: Depressão. Distúrbios temporomandibulares. Dor facial. Idosos. Qualidade de vida relacionada à saúde bucal.

\section{References}

1. Dworkin SF, Huggins KH, LeResche L, Von Korff M, Howard $\mathrm{J}$, Truelove E, et al. Epidemiology of signs and symptoms in temporomandibular disorders: clinical signs in cases and controls. J Am Dent Assoc 1990; 120(3):273-81.

2. Slade GD, Ohrbach R, Greenspan JD, Fillingim RB, Bair E, Sanders AE, et al. Painful temporomandibular disorder: decade of discovery from OPPERA studies. J Dent Res 2016; 95(10):1084-92.

3. Luo Y, McMillan AS, Wong MC, Zheng J, Lam CL. Orofacial pain conditions and impact on quality of life in community-dwelling elderly people in Hong Kong. J Orofac Pain 2007; 21(1):63-71.

4. Dahlstrom L, Carlsson GE. Temporomandibular disorders and oral health-related quality of life. A systematic review. Acta Odontol Scand 2010; 68(2):80-5.

5. Allen PF. Assessment of oral health related quality of life. Health Qual Life Outcomes 2003; 1:40.

6. Ohrbach R, Dworkin SF. The evolution of TMD diagnosis: past, present, future. J Dent Res 2016; 95(10): 1093-101.

7. Miettinen O, Lahti S, Sipila K. Psychosocial aspects of temporomandibular disorders and oral health-related quality-of-life. Acta Odontol Scand 2012; 70(4):331-6.

8. Malheiros AS, Carvalhal ST, Pereira TL, Filho EM, Tonetto MR, Goncalves LM, et al. Association between tooth loss and degree of temporomandibular disorders: a comparative study. J Contemp Dent Pract 2016; 17(3):235-9.

9. Katyayan PA, Katyayan MK, Patel GC. Association of edentulousness and removable prosthesis rehabilitation with se- verity of signs and symptoms of temporomandibular disorders. Indian J Dent Res 2016; 27(2):127-36.

10. Peres MA, Barbato PR, Reis SC, Freitas CH, Antunes JL. Tooth loss in Brazil: analysis of the 2010 Brazilian Oral Health Survey. Rev Saude Publica 2013; 47 Suppl 3:78-89.

11. de Lucena LB, Kosminsky M, da Costa LJ, de Goes PS. Validation of the Portuguese version of the RDC/TMD Axis II questionnaire. Braz Oral Res 2006; 20(4):312-7.

12. Schiffman EL, Truelove EL, Ohrbach R, Anderson GC, John MT, List T, et al. The research diagnostic criteria for temporomandibular disorders. I: overview and methodology for assessment of validity. J Orofac Pain 2010; 24(1):7-24.

13. Pires CP, Ferraz MB, de Abreu MH. Translation into Brazilian Portuguese, cultural adaptation and validation of the oral health impact profile (OHIP-49). Braz Oral Res 2006; 20(3):263-8.

14. Reissmann DR, John MT, Schierz O, Wassell RW. Functional and psychosocial impact related to specific temporomandibular disorder diagnoses. J Dent 2007; 35(8):643-50.

15. Barros V de M, Seraidarian PI, Cortes MI, de Paula LV. The impact of orofacial pain on the quality of life of patients with temporomandibular disorder. J Orofac Pain 2009; 23(1):28-37.

16. John MT, Reissmann DR, Schierz O, Wassell RW. Oral health-related quality of life in patients with temporomandibular disorders. J Orofac Pain 2007; 21(1):46-54.

17. Rener-Sitar K, Celebic A, Stipetic J, Marion L, Petricevic N, Zaletel-Kragelj L. Oral health related quality of life in Slovenian patients with craniomandibular disorders. Coll Antropol 2008; 32(2):513-7.

18. Calderon P dos S, Hilgenberg PB, Rossetti LM, Laurenti JV, Conti PC. Influence of tinnitus on pain severity and quality of life in patients with temporomandibular disorders. J Appl Oral Sci 2012; 20(2):170-3.

19. Scrivani SJ, Spierings EL. Classification and differential diagnosis of oral and maxillofacial pain. Oral Maxillofac Surg Clin North Am 2016; 28(3):233-46.

20. Turner JA, Mancl L, Aaron LA. Short- and long-term efficacy of brief cognitive-behavioral therapy for patients with chronic temporomandibular disorder pain: a randomized, controlled trial. Pain 2006; 121(3):181-94.

21. Murray H, Locker D, Mock D, Tenenbaum HC. Pain and the quality of life in patients referred to a craniofacial pain unit. J Orofac Pain 1996; 10(4):316-23.

22. Reisine ST, Weber J. The effects of temporomandibular joint disorders on patients' quality of life. Community Dent Health 1989; 6(3):257-70.

23. Unell L, Johansson A, Ekback G, Ordell S, Carlsson GE. Prevalence of troublesome symptoms related to temporomandibular disorders and awareness of bruxism in 65- and 75-year-old subjects. Gerodontology 2012; 29(2):e772-9.

24. Sampaio NM, Oliveira MC, Ortega AO, Santos LB, Alves TD. Temporomandibular disorders in elderly individuals: the influence of institutionalization and sociodemographic factors. Codas 2017; 29(2):e20160114.

\section{Corresponding author:}

Tatiana Pereira-Cenci

Department of Restorative Dentistry, Federal University of Pelotas

Rua Gonçalves Chaves, 457, Room 508,

ZIP Code 96015560, Pelotas, Rio Grande do Sul, Brazil Phone/fax: +55 5332256741 - Ext. 135 E-mail: tatiana.cenci@ufpel.tche.br

Recebido: 06/02/18. Aceito: 21/03/18. 